\title{
Modelos afetivo-emocionais: afeto, emoção e desejo no desenvolvimento de sistemas de colaborativos dinâmicos de visualizaçăo de dados.
}

Affective-emotional models: affection, emotion, bond and desire in the

development of collaborative dynamic data visualization systems.

\author{
> José Neto de Faria \\ Universidade Anhembi Morumbi, Brasil \\ josenetodesigner@yahoo.com.br
}

\begin{abstract}
This paper aims to describe the theories behind "feeling analysis" techniques applied to digital electronic devices in order to discuss ways to employ them to establish an "affective-emotional model" that could be used to qualify the data visualization processes. The main goal is to analyze and describe "affective-emotional models" that could be used in "dynamic data visualization systems". In theory, "feeling analysis" techniques, when used to dynamically reconfigure data visualization systems, due to the description of profiles and response patterns, prove to be able to qualify feeding, testing and consulting databases inducting and establishing relations.
\end{abstract}

Keywords: Data visualization; Affection; Emotion; Desire and bond; Induction and freedom.

\section{Introdução}

O contínuo desenvolvimento dos "Sistemas colaborativos dinâmicos de visualizaçáo de dados" levou a questionar-se (Carpendale, 2013; Carusi, 2013; Drucker, 2013; Zuk, 2006a; Zuk, 2006b) o modo como as técnicas de visualização de dados "constroem ou definem a percepçáo da realidade", visto que os dados retirados de um determinado contexto descrevem discursos simplistas e obtusos, que representam na melhor das hipóteses, fragmentos de uma determinada realidade captada, que muitas vezes não representam, padronizam "esterilizam o ato interpretativo" do "Indutor de Atividade", o homem, o sujeito, o indivíduo, o espectador, o ator, o usuário, o interator ou o produtor, que exerce a atividade dos espectadores enquanto operadores (Weibel apud Miranda, 1998, p.207). No entanto, o estudo das técnicas de visualização de dados ainda não foi capaz de abarcar ou discutir as possibilidades que podem emergir da sua associação com as técnicas usadas nos "sistemas afetivo-emocionais".

A pesquisa do uso das técnicas de "análise de sentimentos" e de "analise dos estados de humor", aplicadas em sistemas de visualização de dados poderiam ajudar a identificar, por um lado, os modos de visualizaçáo mais adequados para cada perfil emocional, e por outro, os modos de visualização de dados capazes de promover confrontos entre tendências distintas, éticas, morais e ideológicas, de interpretação. $\mathrm{O}$ estabelecimento de parâmetros que sejam capazes de descrever as possibilidades de uso, relaçóes e implicaçóes positivas e negativas da adoção de "modelos afetivo-emocionais", na conceituação, no desenvolvimento e durante a implantação de
"Sistemas colaborativos dinâmicos de visualização de dados", poderiam ajudar a caracterizar como o "Indutor de Atividade" poderia ser envolvido, induzido a estabelecer laços, despertado a desejar, instigado a participar e a torne-se interprete das representaçóes visuais dispostas sobre a realidade.

\section{Dados e Interpretação dos dados}

Conforme Garrett (apud Santa Rosa; Moraes, 2012, p.28-29) a "arquitetura da informação" preocupa-se em estabelecer uma trama, entre "sistemas de navegação", "sistemas de rotulagem", "sistemas de organização", "indexação", "métodos de busca" e "metáforas visuais", as quais devem ser capazes de integrar as "estratégias e objetivos", o "conteúdo informacional”, a "estrutura organizacional e de disposição no espaço" e a forma da "apresentação geral de todos os dados na interface”, em cada projeto, a fim de qualificar a experiência do "Indutor de Atividade". Pode-se perceber que a tradicional abordagem, da constituição ao modo como os dados são apresentados, reforça a tese de que a apresentação ou a manifestação dos dados é a instância mais próxima do "Indutor de Atividade", mesmo que a distância seja ainda abismal, é possível de ser trabalhada num projeto de visualizaçáo de dados, conforme (Fig.1).

No entanto, ao considerarem-se os estados emocionais, talvez se pudesse encurtar a distância entre o processo de percepção e de interpretação dos dados, através do desenvolvimento de "técnicas de visualização de dados" associadas a "técnicas de análise de sentimentos", as quais poderiam ser capazes de captar, introduzir e de 


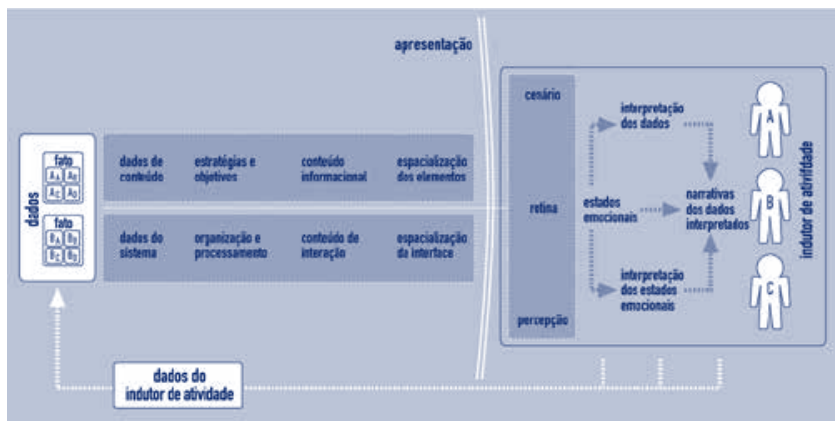

Figure l: Distância entre os dados e o "Indutor de Atividade" num sistema de visualização de dados.

mesclar dados que intensifiquem a relação do "Indutor de Atividade" com o sistema de visualização de dados.

\section{Afeto, emoção, vínculos e desejos}

Os afetos, segundo Espinoza (apud Gleizer, 2005, p.36) são de natureza transitiva, deste modo não são o resultado de uma comparação, mas de uma experiência, promovem a ação não existindo afeto neutro, somente afetos positivos que aumentam a capacidade de agir, como a alegria, e afetos negativos que diminuem a capacidade de agir, como a tristeza. Logo, têm-se dois tipos de afetos: os afetos passivos que se constituem enquanto passividade mental, derivada das paixôes, as quais estáo conectadas as ideias promovidas pela imaginaçáo - desejos passionais; e os afetos ativos que se constituem enquanto atividade mental, derivada dos afetos, os quais estáo conectados as ideias do intelecto - desejos racionais.

A tese de Espinoza (2010, p. 52-53) propóe que em contato com o mundo sensível, dos objetos, a realizaçáo ou não dos desejos, ou do que se deseja, promove através dos afetos primitivos, de alegria e de tristeza, uma relaçáo obsessiva de amor ou ódio com o objeto (veneração e/ou destruição). Essa projeção sobre o objeto conforme a fonte do desejo, interna ou externa, é natural, presente no ser, fruto de uma revelaçáo promovida pelo intelecto; ou uma prospecção de um fim desejável e realizável em si, fruto da imaginação passional.

No mundo, o indivíduo, diferente de um laboratório, está naturalmente exposto a múltiplos estímulos e conteúdos cognitivos (processos mentais e memórias), deste modo a exposição a dois objetos por associação, contiguidade ou semelhança, cria um processo no qual se pode associar sentimentos positivos ou negativos a um mesmo objeto independentemente da experiência real que tivesse com o objeto, a chamada "derivadas da mera justaposição espaço-temporal” (Gleizer, 2005, p.42).

Os "objetos emocionalmente competentes", que promovem "estímulos sensoriais", são responsáveis pela origem imediata do sentimento, porém a alteraçáo do estado do corpo advém do "objeto imediato", derivado do conjunto de "estímulos processados", e a percepçáo, que constitui a essência do sentimento, o contato com o que "representa o objeto".

"Seja como for, o objeto do desejo e as memórias pessoais que dizem respeito a esse objeto interagem mútua e abundantemente.
As ocasióes passadas de desejo, as nossas aspiraçóes passadas, os nossos prazeres passados, reais ou imaginários, todos eles contribuem para que o desejo se projete de forma particular na nossa mente" (Damasio, 2004, p.103).

O desejo existe consciente e ao mesmo tempo inconsciente, recebe influências do mundo exterior e interior, "é vontade, ambição, inclinação do espírito para algo cuja a posse ou realizaçâo causaria prazer" (Machado, 1981, p.243 apud Lopes, 2005, p.461). O desejo é o emprego de uma energia direcionada ao simbólico, ao "objeto cultural" que é considerado pelo "Indutor de Atividade" como gerador de prazer, de alegria e satisfação (David-Ménard, 1996, p.114).

O desejo estimula a necessidade do encontro, no "Indutor de Atividade", entre o mundo interior e o mundo exterior, propicia na aproximação com o "Outro" a revelação da sua natureza, reforçando o entendimento sobre as suas profundas necessidades. Segundo Lacan (apud David-Ménard, 1996, p.120-121) o desejo é entendido como a "falta" do objeto que irá diferenciar o sujeito e propiciará a sua individualização. Para que o desejo ocorra é necessário que o indivíduo perceba "a falta" do "Outro", ou seja, do "objeto cultural". Esta sensaçáo de falta irá atravessar a relação do "Indutor de Atividade" com os seus "objetos culturais", sensação quase sempre de ausência, de falta e de fragmentação do seu ser. Esse objeto, entendido como "objeto cultural", seria o promotor e propulsor da dignidade do "Indutor de Atividade" na sua sociedade, ferramenta ou conjunto de construçóes simbólicas, capazes de comunicar para si e para os outros a essência do seu ser.

\section{Sistemas afetivo-emocionais}

Os "Sistemas afetivo-emocionais" ajudam os homens, os animais e as máquinas no processo de adaptação ao meio ambiente natural e cultural, por meio da promoção de processos de comunicação os quais permitem o inter-relacionamento em um mesmo sistema e entre sistemas distintos, e consequentemente, níveis mais elevados de socialização.

"Vários teóricos argumentam que algumas emoçóes selecionadas são básicas ou primárias - são adotadas pela evolução devido à sua capacidade comprovada de facilitar respostas adaptativas para a vasta gama de demandas e oportunidades que uma criatura enfrenta em sua vida diária. Cada emoção básica é posta para servir uma determinada função (muitas vezes biológica ou social), decorrente em determinados contextos (provocando condiçóes), para se preparar e motivar uma criatura a responder de forma adaptativa" (Breazeal, 2001, p.583.).

Pode-se dizer que todas as relaçóes emocionais são constituídas por "um evento precipitante; uma avaliação afetiva desse evento; uma expressão característica (rosto, voz, postura); e por fim, tendências de ação que motivam uma resposta comportamental" (Breazeal, 2001). Deste modo, os "sistemas afetivo-emocionais" devem ser capazes de perceber o acontecimento, analisar, avaliar e ponderar sobre o acontecimento, comunicar emocionalmente a percepçáo do acontecimento, e para finalizar, estabelecer uma resposta, que corresponde à definiçáo de um conjunto de açóes. 
As "análises de sentimentos" são geralmente estabelecidas em função de um conjunto de dados previamente definidos, que recebidos, analisados e ponderados podem indicar um determinado tipo de sentimento. Logo, os "Sistemas afetivo-emocionais" desenvolvidos não conseguem o mesmo desempenho quando utilizados em "análises de sentimentos" de assuntos distintos, pois os algoritmos que são utilizados com precisão dentro de um contexto de uso, na maioria das vezes quando utilizados em outro domínio perdem sua precisão.

As "análises de sentimentos" podem ser utilizadas para definir comportamentos, estados de humor, treinar o comportamento de dados, identificar intençóes, identificar tendências interpretativas e promover processos de aprendizado. Deste modo, existe um conjunto de técnicas que buscam identificar e estabelecer uma ponderação e hierarquização entre os dados que representam os sentimentos. Existe também um conjunto de técnicas que analisam a "intensidade de sentimentos”, que são utilizadas para identificar os estados de humor dos "Indutores de Atividade" em vários serviços prestados por sistemas eletrônico digitais.

Contudo, o "sentido da linguagem" quando interpretado por "Sistemas afetivo-emocionais" depende de um conjunto mais extenso de técnicas de análise da "extensão léxica", que utiliza: sistemas de mineração de dados ou data mining; aplicação de uma "coleção de termos" ou test corpus e aplicação de um "conjunto de regras"; sequenciamento de palavras; associação de palavras não pertencentes ao texto analisado; sistemas de rotulação por dataset; e por fim, sistemas de rotulaçáo com codificadores humanos (Thelwall; Buckey, 2012).

Contudo, tanto as técnicas de identificação da "intensidade dos sentimentos" quanto às técnicas de análise da "extensão léxica" requerem a intervenção humana, pois "necessita de anotação no test corpus ("coleção de escritos de teste") e uma pequena quantidade adicional de anotaçóes para ajudar também a selecionar os termos", visto que o trabalho humano parece ser particularmente importante para temas estritamente focados, pois evitam que pequenos erros de classificação possam resultar em diferenças significativas .

Os "Sistemas afetivo-emocionais" são desenvolvidos para terem a capacidade de aprender, a fim de poderem, através do tempo, atualizar-se para identificar e responder de modo mais eficiente os perfis dos "Indutores de Atividade". Neste processo de aprendizado, são entre cruzados os padrôes de sentimentos identificados para que sejam estabelecidos padróes entre os padróes anteriormente identificados. Assim, existem basicamente duas abordagens, a do "aprendizado de máquina" e do "aprendizado lexical", embora muitos dos algoritmos tenham elementos de ambos.

Todos os "Sistemas afetivo-emocionais" são baseados em "modelos afetivo-emocionais", os quais devem delinear de modo adequado cada tipo de "análise de sentimento" que se busca fazer em consonância com um contexto determinado. Deste modo, um "modelo afetivo-emocional" para "sistemas de visualização de dados" só pode ser traçado em forma de linhas gerais, pois para cada conjunto de dados a serem visualizados e para cada interface e processo de interaçáo definido, o modelo deverá ser redesenhado e especializado.

\section{Metodologia}

Com o intuito de se estabelecer um "modelo afetivo-emocional" para ser utilizado em "Sistemas colaborativos dinâmicos de visualização de dados", foram estabelecidas seis etapas de pesquisa: busca da identificação dos tipos de dados e dos estágios do sistema passíveis de serem observados por "análise de sentimentos"; caracterizaçâo dos tipos de relaçóes afetivo-emocionais que poderiam emergir do sistema; estudo dos possíveis perfis que poderiam ser identificados; estudo de como os "modelos afetivo-emocionais" podem ajudar grupos de "indutores de atividade" a adaptarem-se ao trabalho colaborativo e ao mesmo tempo fomentar a socialização; esboço ou caracterização de um "modelo afetivo-emocional" para sistemas de visualização de dados; e por fim, análise e discussão dos resultados.

\section{Modelo afetivo-emocional}

Os "Sistemas colaborativos dinâmicos de visualização de dados" buscam promover a observação e a compreensão de conjuntos de dados, através de sucessivos ensaios e simulaçóes, os quais propiciam modos de apresentação e de interaçáo capazes de revelar as relaçóes existentes entre os dados. Os "Sistemas afetivo-emocionais" são baseados em modelos que delineiam o conceito, o conjunto de princípios, os meios, as técnicas e as ferramentas que são usadas a fim de identificar, avaliar, induzir e efetivar estados emocionais, de modo a ajudar os dispositivos eletrônicos digitais a perceber e a responder com eficiência, as necessidades de intermediação do "Indutor de Atividade".

Assim, os sistemas apresentam naturezas e objetivos diferentes. Enquanto os "Sistemas de visualização de dados" têm como principal preocupação promover a apresentação visual de um determinado conjunto de dados, muitas vezes sem relaçáo nenhuma com o "Indutor de Atividade", os "Sistemas afetivo-emocionais" buscam captar conjuntos de dados que são capazes de determinar estados emocionais do "Indutor de Atividade". A natureza lógica faz com que os sistemas trabalhem com "Tipos de Dados" diferentes, os "Sistemas de visualização de dados" utilizam na maioria dos casos dados externos advindos de bancos de dados, e os "Sistemas afetivo -emocionais" dão preferência ao uso de dados captados durante os procedimentos de interação executados pelo "Indutor de Atividade".

Assim, o "Modelo afetivo-emocional" para os sistemas de visualização de dados pode basicamente se apropriar de três "Tipos de Dados", produzidos pelos "Indutores de Atividade": os derivados de procedimentos de alimentaçáo de conteúdo do sistema; os dos procedimentos de consulta; e os dos procedimentos de navegaçáo e interação.

Outra diferença, resultante da natureza do sistema, refere-se ao "Tipo de Participação" ou qualidade de uso, que cada dispositivo eletrônico digital pode promover ao "Indutor de Atividade": "individual", o indivíduo usa o sistema para executar o conjunto de operaçôes básicas disponíveis; "individual assistido", o indivíduo usa o sistema para executar as operaçóes, com o sistema ajudando a realizar e a induzir a realização de outras operaçóes; "colaborativo", conjuntos de indivíduos usam o sistema para realizar operaçôes que podem ser compartilhadas, nele são potencializadas as trocas e as colaboraçóes; "colaborativo assistido", conjunto de indivíduos usam 


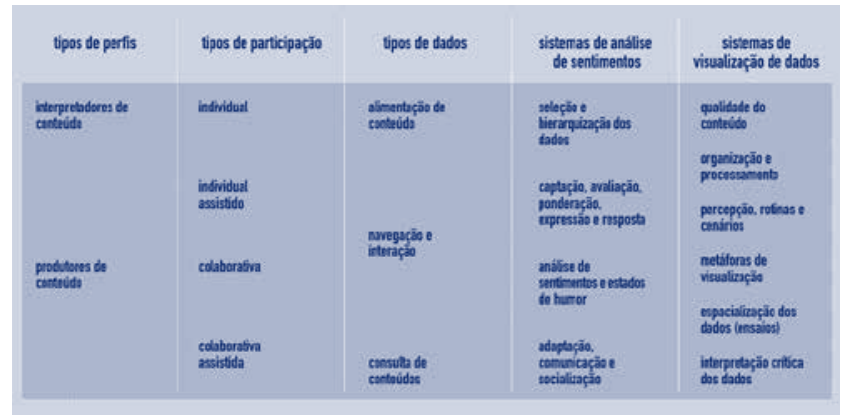

Figure 2: Parâmetros envolvidos na definição de "Modelos afetivo-emocionais" para "Sistemas de visualização de dados".

o sistema para realizar operaçóes e trocas de forma colaborativa, com o sistema ajudando a realizar e a induzir a realização de outras operaçóes para intensificar o processo colaborativo.

O "Modelo afetivo-emocional" para sistemas de visualização de dados devem considerar dois "Tipos de Perfis" de "Indutores de Atividade", classificados pelo tipo de contribuição que exercem com o sistema: os "Produtores de conteúdo", os quais alimentam o sistema com dados; e os "Interpretadores de conteúdo", os quais consultam o sistema sem contribuir com novos dados de conteúdo. Dos "Produtores de conteúdo" consegue-se obter dados de alimentação, consultas, navegação e interação, enquanto que dos "Interpretadores de conteúdo" só pode-se obter dados de consultas, navegação e interaçáo, para a realizaçáo de "análises de sentimentos", conforme (Fig.2).

\section{Considerações finais}

O principal motivo para o uso de "Modelos afetivo-emocionais" em sistemas de visualização de dados pode ser, apropriar-se dos padróes comportamentais de uso, captados, analisados, mapeados, mimetizados e estruturados como traços dos perfis, dos "Indutores de Atividade", a fim de promover processos miméticos de resposta que potencializem pela empatia, pelas intensóes similares ou opostas, pelas interpretaçóes e posicionamentos e pelos alinhamentos ideológicos, o relacionamento entre os colaboradores, e também, com o próprio sistema.

$\mathrm{O}$ ato de escolher os dados que serão inseridos no sistema (input) ou de escolher os dados que serão posteriormente visualizados (output) caracterizam tendências de seleção, as quais podem ser utilizadas para definir perfis afetivo-emocionais, perfis filosófico -ético, perfis moral-políticos, ou qualquer tipo de traço que possa ser utilizado para adaptar o sistema aos "Indutores de Atividade".

A sinergia e consequentemente a aproximação dos colaboradores pode também ser utilizada para tornar o ambiente de navegação e interação mais amigável aos "Indutores de Atividade", que poderiam mais rapidamente reconhecer os padrôes de resposta do sistema. Caracterizar as relaçóes afetivo-emocionais no âmbito da manipulação de um sistema de visualização de dados pode servir para rastrear os diferentes perfis dos "Indutores de Atividade", os quais podem ser utilizados na adaptação ou socializaçáo pelo fomento da participação e do trabalho colaborativo.
Contudo, a especialização do sistema de visualização, na geração da apresentação de certos tipos de dados relacionados a assuntos e áreas de conhecimentos distintas, exige não só do sistema de visualização, mas também do "Modelo afetivo-emocional" o mesmo nível de especialização.

Deste modo, os parâmetros que devem ser estabelecidos para o "Modelo afetivo-emocional" devem ser traduzidos em diretrizes para a implantação concomitantemente nos "Sistemas colaborativo dinâmico de visualização de dados”, e devem contemplar:

a. O delineamento de um conjunto de relaçóes afetivo-emocionais que vinculem os "Indutores de Atividade", o qual deve ser implantado também na forma de um conjunto de metáforas visuais capazes de representá-las;

b. A descrição do modo como a "análise de sentimentos" sobre os textos imputados no sistema pode ser usada para averiguar as tendências de posicionamento crítico do "Indutor de Atividade", a qual deve ser traduzida em conjuntos de metáforas de visualização, capazes transparecer para os colaboradores o modo como aborda o assunto;

c. A descriçáo do modo como a "análise de sentimentos" pode verificar padrôes entre os padróes de diferentes "Indutores de Atividade", a qual deve ser traduzida em mecanismos que aumentem a sinergia e aproximem os colaboradores;

d. A interpretação pelo sistema do posicionamento de cada texto imputado de modo a identificar similaridades e oposiçóes nas abordagens críticas, a fim de aproximar e comparar os diferentes textos, a qual deve ser traduzida em sistemas de apresentação da informação capazes de promover a observaçáo dos dados, mas relevando e indicando visualmente as tendências.

No entanto, a pesquisa não atingiu a profundidade necessária para descrever um conjunto de parâmetros capazes de definir um "Modelo afetivo-emocional" para ser implantado num sistema de visualização de dados. Pois, devia-se deter com mais atenção, na descrição das qualidades dos dados que representam os estados emocionais dos "Indutores de Atividade", a fim de identificar como estes podem se manifestar como conteúdo ou na qualidade de mecanismos de navegaçáo e interação. Outro ponto importante, descritos os perfis dos "Indutores de Atividade", trata-se de como selecionar e utilizar certos traços dos perfis para promover a aproximação e a colaboração no uso dos sistemas de visualização de dados. Assim, estudar a implantação de um "Modelo afetivo-emocional" num sistema de visualizaçáo de dados existente, pode ajudar a compreender melhor as implicaçôes da integração das duas naturezas, revelando o possível impacto na observação crítica dos dados apresentados nos ensaios. Da mesma maneira, como pode ajudar a compreender os modos como os "Indutores de Atividade" perceberiam a interação com o sistema de visualização.

Como os sistemas de visualizaçáo de dados focam na apresentação dos dados e os sistemas de análise de sentimentos foram na captação e identificação de estados emocionais, a continuação do estudo da associação poderia ajudar a produzir sistemas de visualizaçáo de dados mais propensos a diminuir a distância entre o "Indutor de Atividade" e os dados de conteúdos. Pois, existe um 
abismo que tem que ser transposto entre a capacidade de captar os estados do "Indutor de Atividade" e a capacidade de organizar e apresentar dados de conteúdos, a fim de que conteúdo e indivíduo possam ser integrados, o que tornaria ao mesmo tempo, o sistema mais complexo de ser concebido, mas as suas interfaces mais "transparentes".

\section{Referências}

Breazel, C. (2001). Affective interaction between humans and robots. In: Kelemen, J.; Sosík, P. Proceedings of the 6th European Conference on Advances in Artificial Life. (pp.582-591). Berlin, BE: Spring-Verlog. Retrieved from: http://link.springer. com/ chapter/10.1007 \%2F3-540-44811-X_66.

Carpendale, S. (2013). Innovations in visualization. In: Samavati, F. F.; Hawkey, K. (Ed.). GI'13: Proceedings of the 2013 Graphics Interface Conference. Toronto, TO: Canadian Information Processing Society Toronto. Retrieved from: http://innovis.cpsc. ucalgary.ca/innovis/ uploads/Publications/Publications/13Carpendale-GI.pdf.

Carusi, A. (2010). Technologies of representations: images, visualizations and texts. In: Proceedings of the computational turn. Enscheda: University Twente. Retrieved from: http:// athanasius.stanford.edu/Readings/ Carusi.pdf.

Castilho, P. T. (2007). Alusôes Lacanianas à falta a partir do modelo crístico: um lugar para a crença repousar. Rio de Janeiro, RJ: The Scientific Electronic Library Online - SciELO. Retrieved from: http://www.scielo.br/pdf/pc/ v19n2/a12v19n2.pdf.

Damasio, A. R.. (2004). Em busca de Espinoza: prazer e dor na ciência dos sentimentos. São Paulo, SP: Companhia das Letras.

David-Ménard, M. (1996). Desejo. (pp.114-120). In: Kaufmann, P. Dicionário enciclopédico de psicanálise: o legado de Freud e Lacan. Rio de Janeiro, RJ: Jorge Zahar Editora.

Drucker, J. (2011). Humanities approaches to graphical display. In: Swanstrom, L.; Pressman, J. (Ed.). Digital Humanities Quarterly - DHQ. Providence: Alliance of Digital Humanities
Organizations. Retrieved from: http://www.digitalhumanities. org /dhq/vol/5/1/000091/ 000091.html.

Gleizer, M. A. (2005). Espinosa e a Afetividade Humana. Rio de Janeiro, RJ: Jorge Zahar Editor.

Lopes, M. C. O. (2005). Design de ludicidade: do domínio da emoção no desejo, à racionalidade do desígnio, ao continuum equifinal do desenho e à confiança que a interacção social lúdica gera. Lisboa, LIS: Biblioteca On-line de Ciências da Comunicação - BOCC. Retrieved from: http://www.bocc. ubi.pt/ pag/lopes-conceicao-design-ludicidade-dominio-emocao-desejo.pdf.

Miranda, J. B. (1998). Da interactividade: crítica da nova mimesis tecnológica. In: Giannetti, C. (Org.) Telemática: telecomunicaçáo, internet e ciberespaço. (pp.179-233). Lisboa, LIS: Relógio D’Água.

Santa Rosa, J. G.; Moraes, A. (2012). Avaliação e projeto no design de interfaces. Teresópolis, RJ: Editora 2AB.

Spinoza, B. B. (2010). Ética. São Paulo, SP: Autêntica.

Thelwall, M.; Buckey, K. (2012). Topic-based sentiment analysis for the social web: the role of mood and issue-related words. New York, NY: Journal of the American Society for Information Science and Technology; John Wiley \& Sons, p.1-17.

Zuk, T.; Carpendale, S. (2006a). Heuristics for information visualization evaluation. In: BELIV 2006: Proceedings of the workshop beyond time and errors: Novel evaluation methods for information visualization, held in conjunction with the working conference on advanced visual interfaces (AVI 2006). Venice, VE: ACM Press. Retrieved from: http://innovis.cpsc.ucalgary.ca/ innovis/ uploads/Publications/Publications/Zuk_2006_HFI.pdf.

Zuk, T; Carpendale, S. (2006b). Theoretical analysis of uncertainty visualizations. In: Proc. SPIE \& IS \& T Conference electronic imaging, Vol. 6060: Visualization and Data Analysis 2006. New York, NY: AIP Publishing LLC. Retrieved from: http://innovis. cpsc.ucalgary.ca/innovis/uploads/Publications/Publications/ Zuk_2006_TheoreticalAnalysis.pdf. 